أسس وعناصر التصميم المستخدمة في الرسوم الصرية القديمة

\author{
إعـــــلـداد

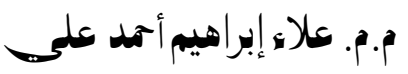 \\ مساعد محاضر بكلية الفنون والعمارة. قسم الفنون \\ جامعة عمر المختار . فرع درنة ـ ليبيا
}

مجلة بحوث التربية النوعية - جامعة المنصورة

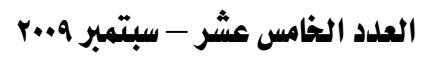




\title{
أسس وعناصر التصميم المستخدمة في الرسوم المرية القديمة
}

\author{
إعــداد \\ م.م. علاء إبراهيم أحمد علي
}

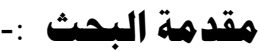

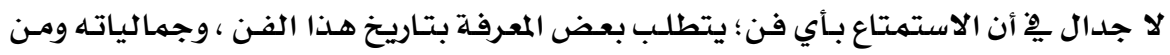

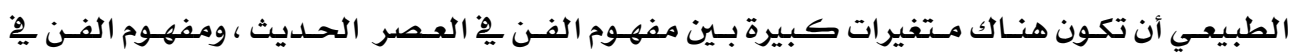

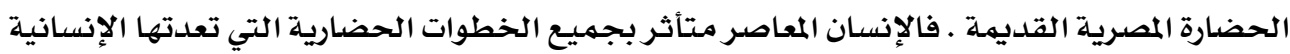

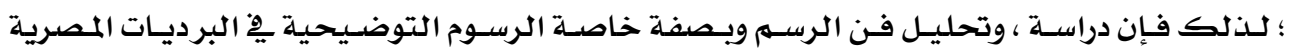

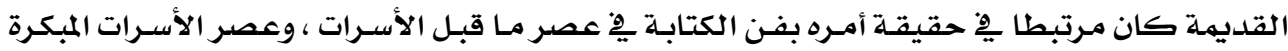

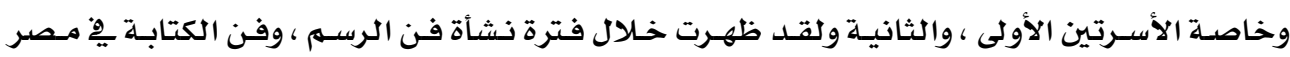

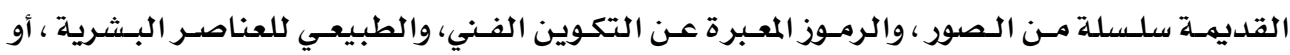

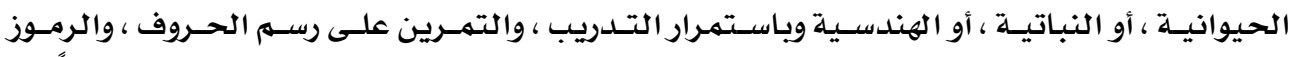

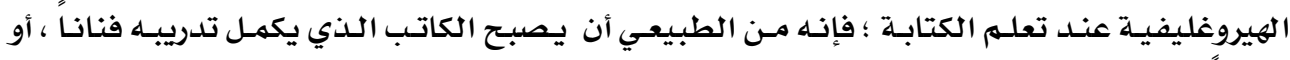

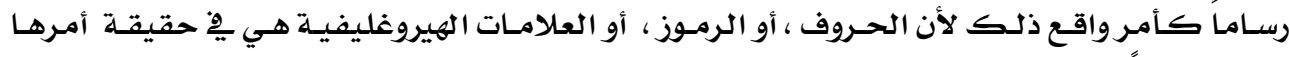

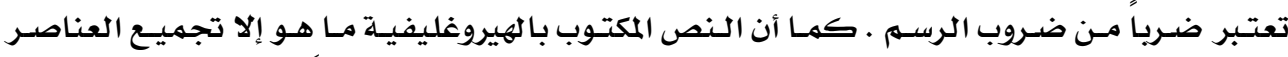

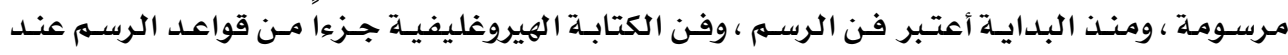
قدماء المصريين . (1) قومنئ

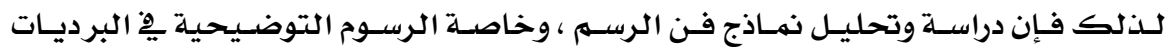

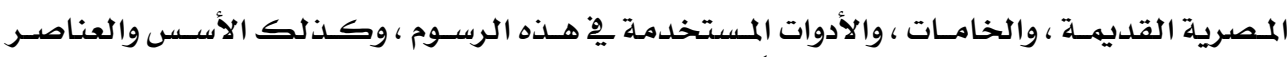

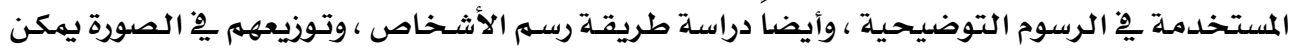

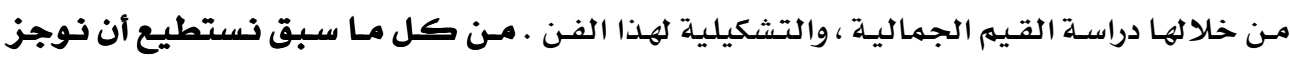

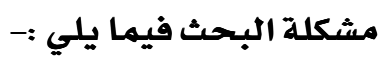
كيفية استخلاص القيم التشكيلية للرسوم الموجودة يْ الرسوم المصرية القديمة .

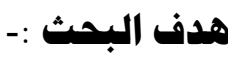
يهدف البحث إلي دراسة أسس وعناصر التصميم فِّ الرسوم المصرية القديمة إلى :(') وليم هـ ـ بيك : فن الرسم عند قدماء المصريين ، ترجمة مختار السويفى ، مراجعة د ـ أحمد قدري ، الدار المصرية

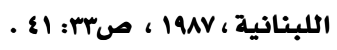


ا . عرض الموضوعات التي تناولها الكتاب يِّ مصر القديهـة، وتطورها .

r. توضيح مدى أهمية أسس وعناصر التصميهم كأول صورة لتصميمات فنون الكتاب .

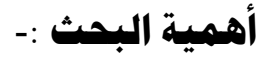

تكمن أهمية البحث هِ: :-

ا. تحقيق أكبر قدر ممكن من هذه الأهداف ؛ وذلك مـن خـالال متابعـة التطور التـاريخي للرسـوم

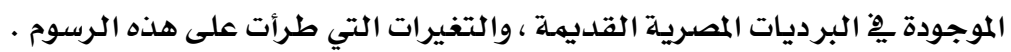

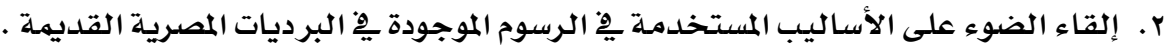

فروض البمث :-

يفترض الباحث عدة فروض فِ شكل تساؤلات على النحو التالي :-

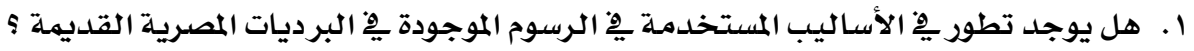

r. هل يمكن الاستلهام من تلك الرسوم الشكل المميز لطبيعتنا الفنية المعاصرة ؟

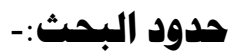

ا ـ . ملدود زمانية :-

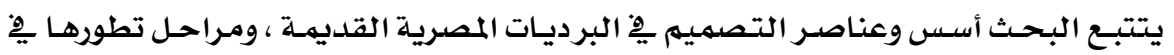

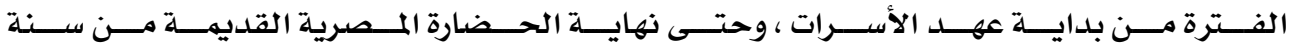

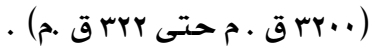

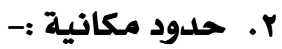

يتناول البحث أسس وعناصر التصميهم يِّا البرديات المصرية القديمـة .

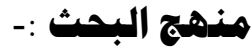

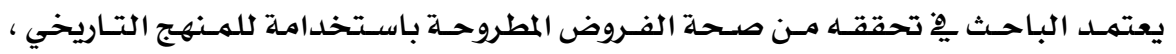

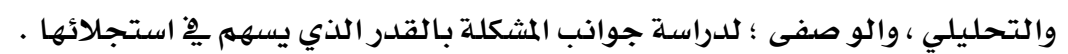

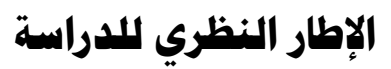

أسس وعناصر التصميم المستخدمة فِ الرسوم المصرية القديمة

أولاً:- أسس التسميم التصميم.

ع- التوازن.

ثانيا:- عناصـر التصميم.

1- النقطة. 
الشكل أو المظهر العام وقيمته تحسده الصفات التي تتـوافر لـه يخ تجميـع عناصـر تكوينـه مـن

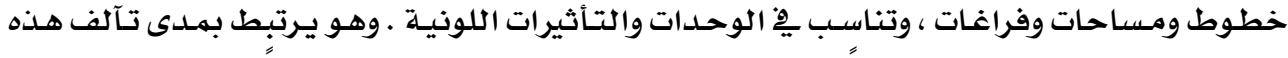

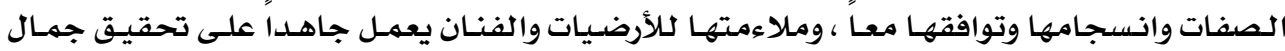
الشكل العام يُ إنتاجـه ، ويحاول دائما أن يصل إلى الإجادة يْ كل أعماله ؛ ويتطلب ذلك مهارة وقدرة فنية خاصة .

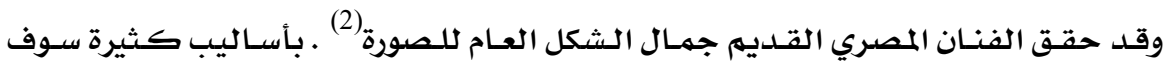
نتحدث عنها فيها يلي :أول : أسس التصعهيم . | التباين :- الت

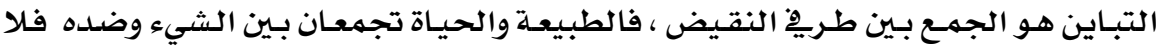

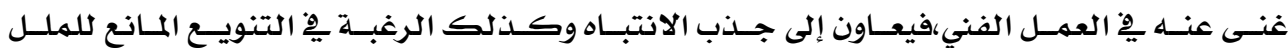

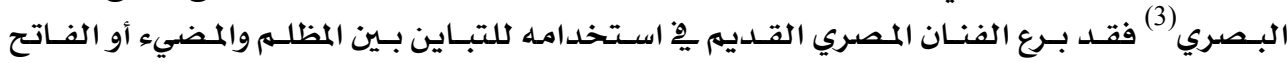
والقـاتم، وذلـك يـرجـع إلى عـدم اسـتخدامه بكثرة لـدرجـات الظل والنـور حتـى لا يسـاعد ذلـك على التعـبير بـالعمق أو الإحسـاس بـالمنظور. (شـكل رقهم 1) حيـث نشاهد يِّ الـهورة التبـاين بـين الأبـيض

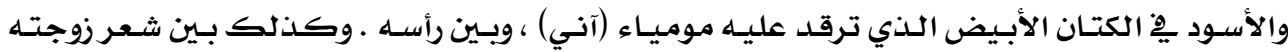

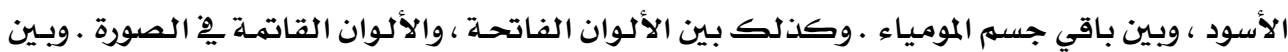

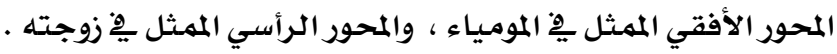

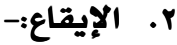

الإيقــاع هـو تنظـيم للفواصـل الموجـودة بـين وحسدات العمـل الفـني ،وقـد يكـون هـذا التتظـيم لفواصل بـين الحجوم ، أو الألوان ، أو لترتيـب درجاتها ، أو لتتظيهم الاتجـاهات بـين عنـاصـر العهـل الفـني

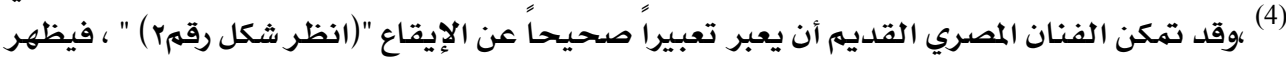

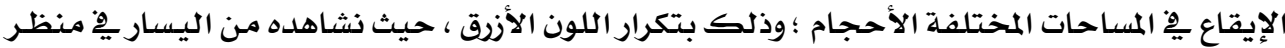

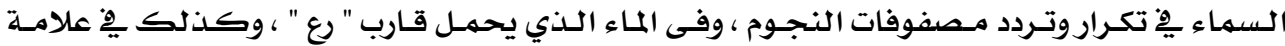
الحياة " عنتخ " الحن r.

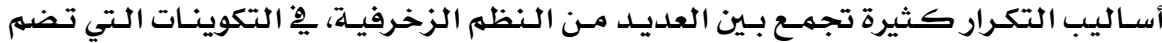

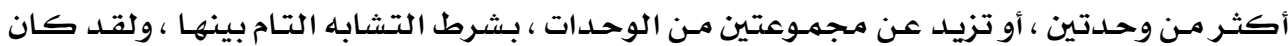

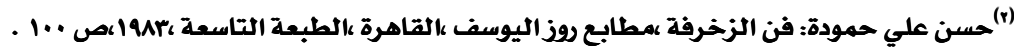

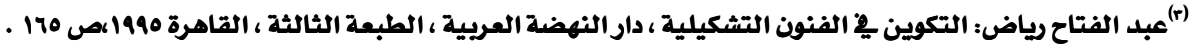
(ء ) د. فتح الباب عبد الحليم ، د. أحمد حافظ : التصميم مِ الفن التشكيلي ، الناثر عالم الكتب ، مطبعة سجل العرب ، 
للفنـان المصري القديهم بـاع طويل ِِّ إبداع وتخطيط العديد من هذه التكرارات، بهـا خلفـه مـن نقوشـات

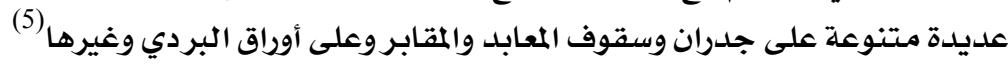
وسوف نتحدث عن أهم أنواع وأوضاع التكرارات يِّ البرديات المصرية القديهـة .

$$
\text { أنواع التكرارات : - أنوات }
$$

أ- التكرار العادي : وفيه تتجـاور وحسدات الزخرفة ، أو عناصـرها يِّوض وضع واحسد ثابـت ( انظـر

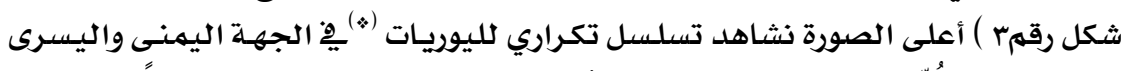

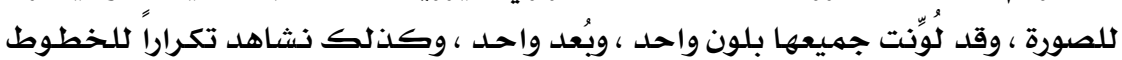

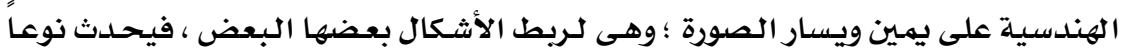

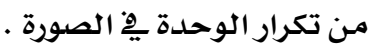

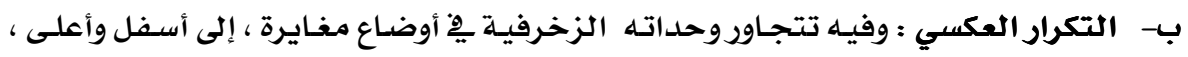

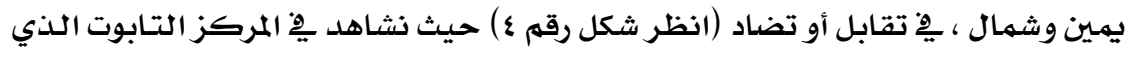

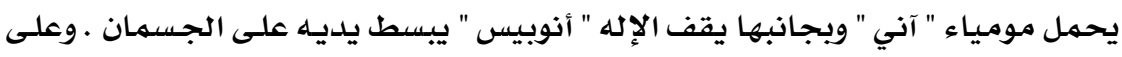

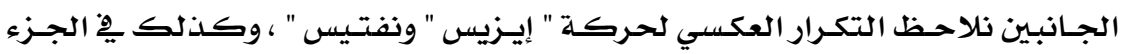

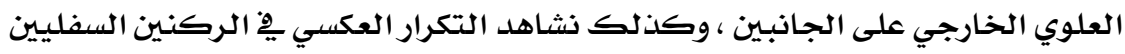

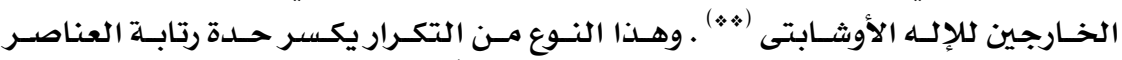

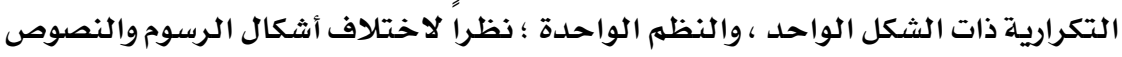

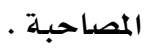

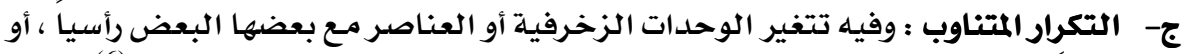

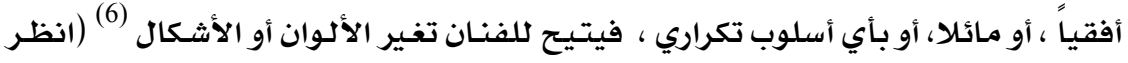

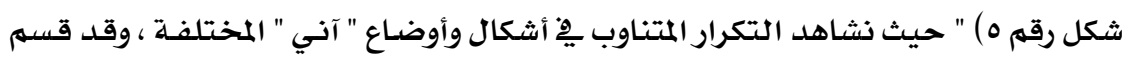

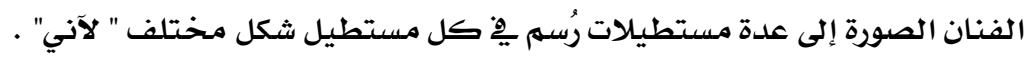

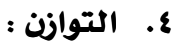

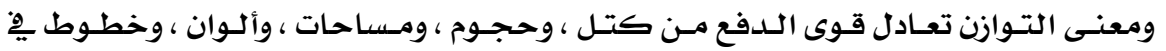

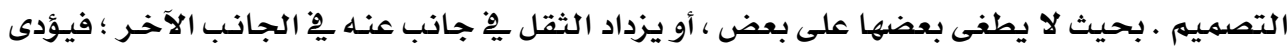

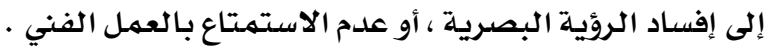

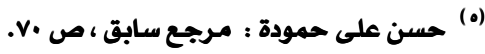
(•) (•) اليوريات : الحيات جمع حيه وهى أنثى الثعبان.

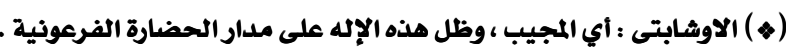

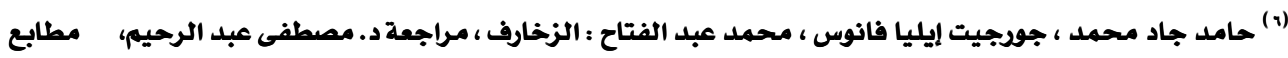

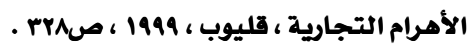




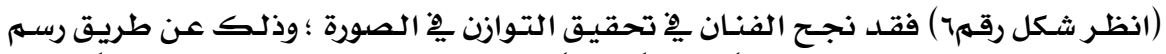

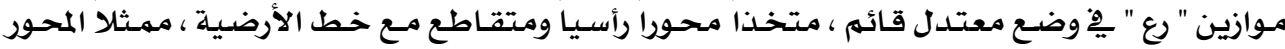

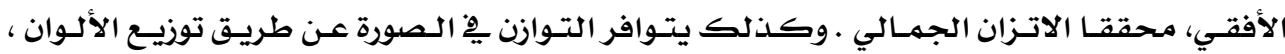

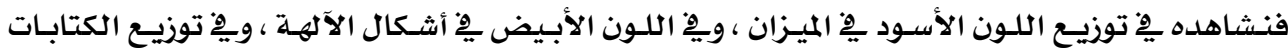
المصاحبة للصورة ، ويٌْ الفراغات حول أشكال الآلهة .

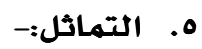

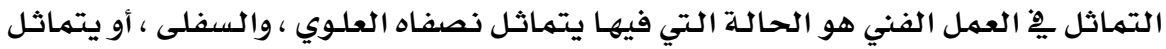

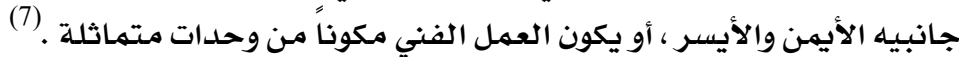

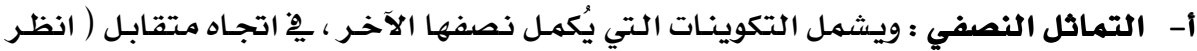

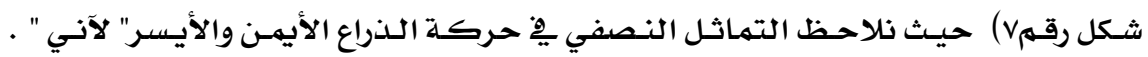

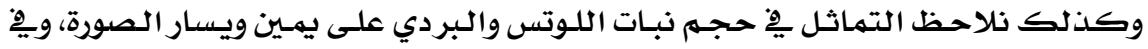

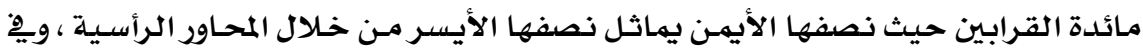

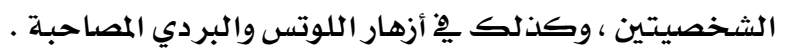

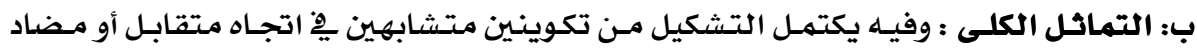

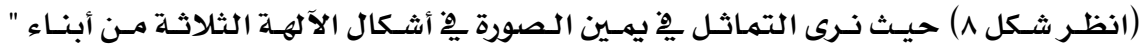

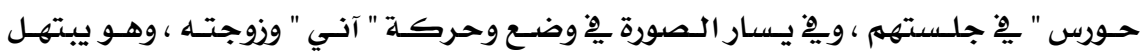

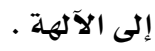

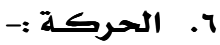

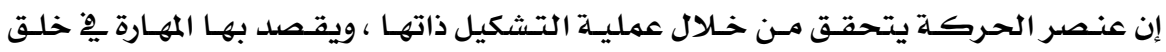

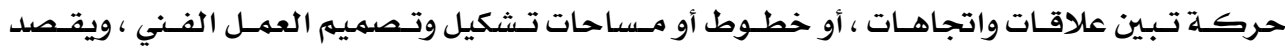

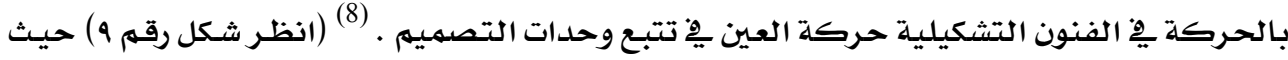

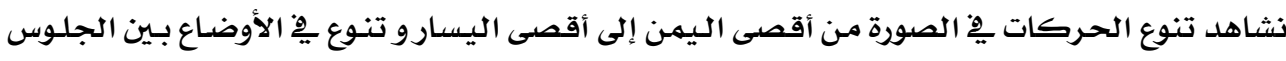

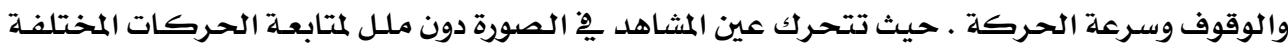
مما جعل الصورة تنطق بالحركة والحيوية .

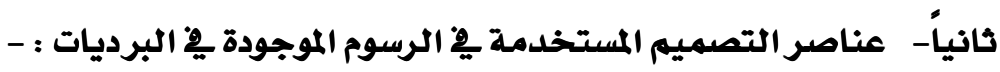

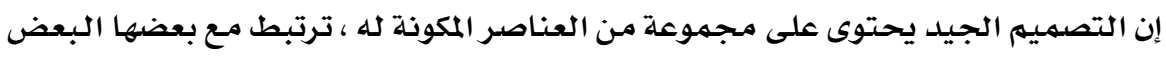

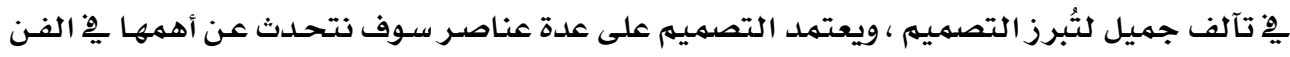

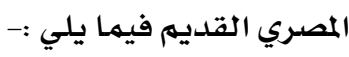

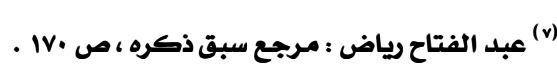

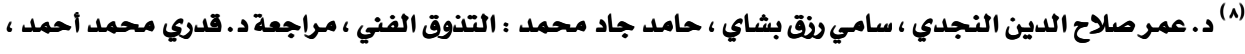

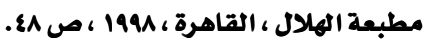




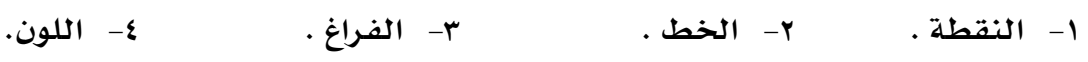

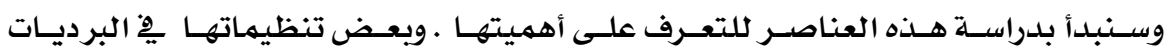

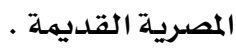

$$
\text { - - 1- النقطة :- }
$$

تعريفها هندسياً : النقطة الهندسية هي وضع مجرد مـن الطول والعرض والارتفاع ، أي أنها

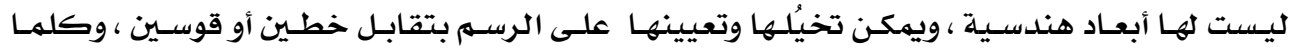

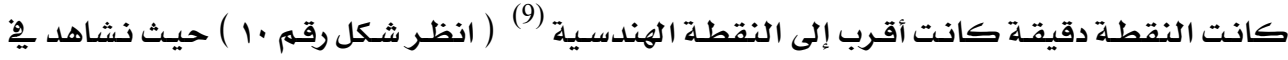

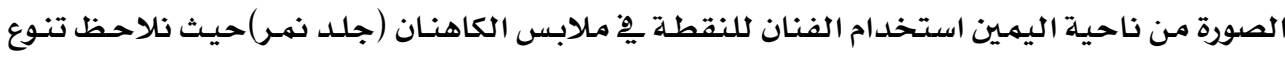

\section{Y- الخـط:-}

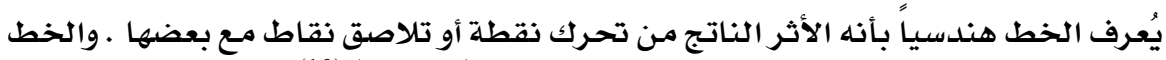

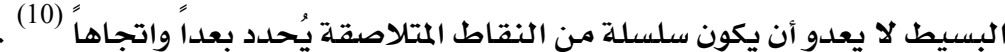

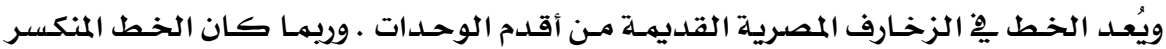

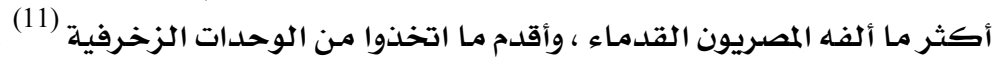

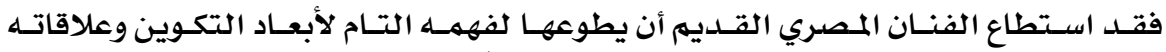

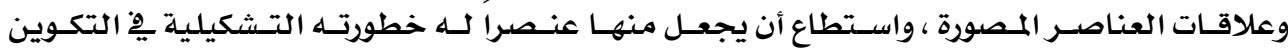

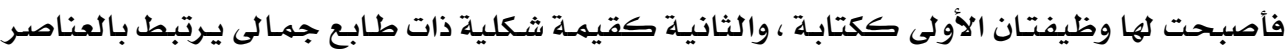

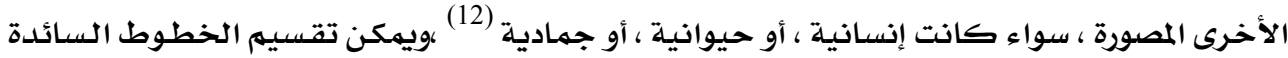

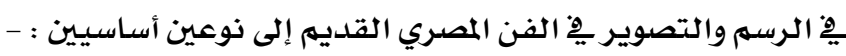

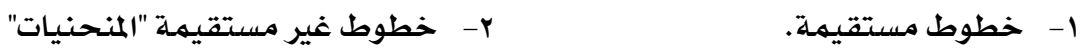

وينـدرج تحـت كل نوع مـن هـذين النـوعين مجموعـة مـن الخطوط لكل منهـا طبيعسة مـرئيسة

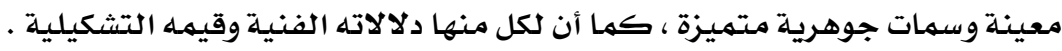

الخطوط المستقيمة : - الخميت

للخط المستقيهم ِِِ العمل الفني إحسـاس صسارم صـريح وقوى ، ولكنـه غير مـريح مـن ناحيـة "

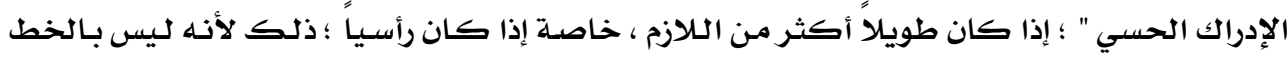

(1) حامد جاد محمد ، وآخرون : مرجع سبق ذكره ، ص 79 . 79

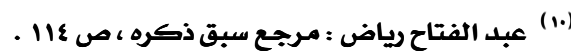

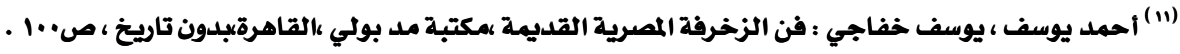

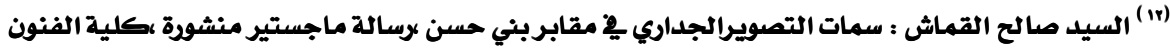

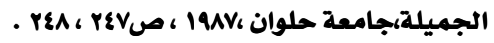




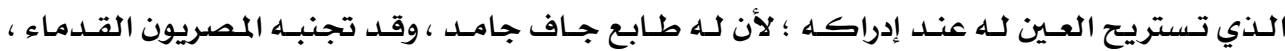

فأدخلوا المنحنيات يخ خطوطهم .

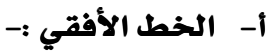

تعمل الخطوط الأفقيـة كأرضـية أو قاعدة لكل مـا هـو فوقها ؛ ولـذلك فإنـه ينبغي أن نرىى

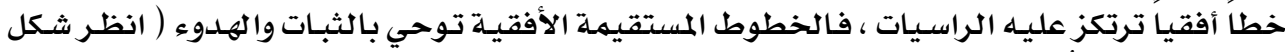

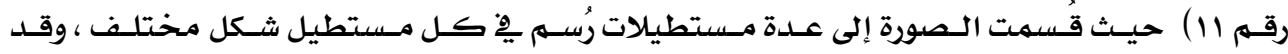

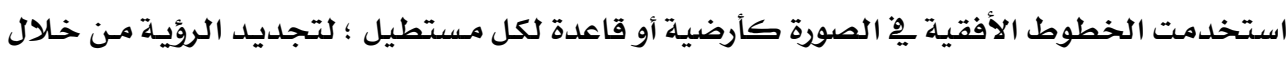
التجوال بين عناصر ومفردات العمل الفني وكسر حدة الرتابة والملل لمزيد مـن الاستمتاع .

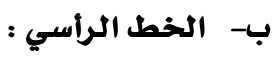

ترمـز الخطـوط الرأسـية إلى القـوى النـاميـة ، وفى تلاقى الخطـوط الرأسيـة والأفقيـة إقامــة

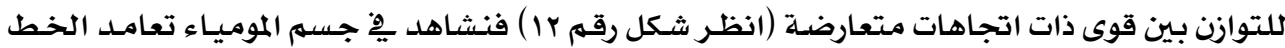

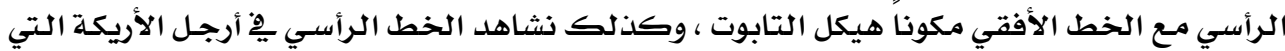

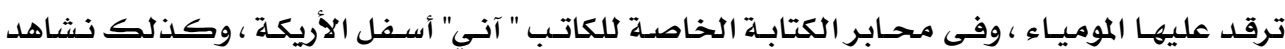

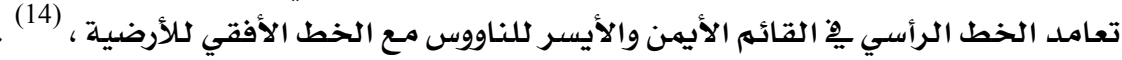

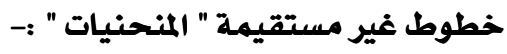

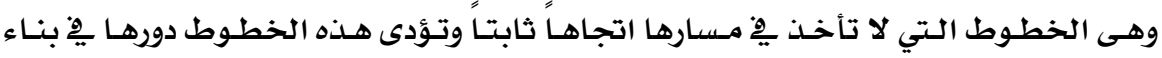

$$
\begin{aligned}
& \text { العمل الفني بجانب الخطوط المستقيمـة ، ومـن أمثلتها مـا يلي : - }
\end{aligned}
$$

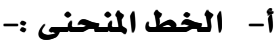

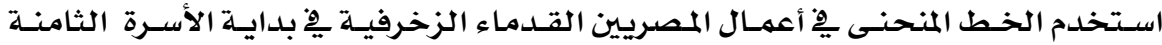

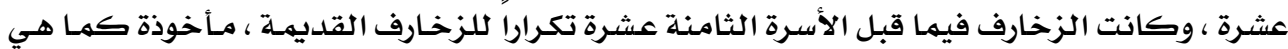

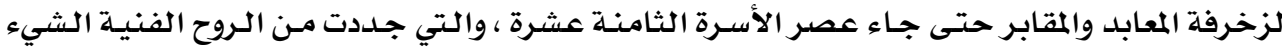

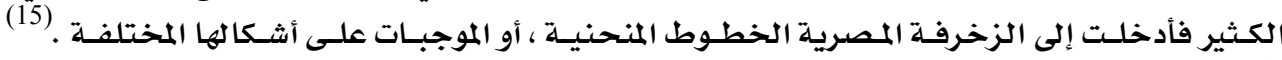

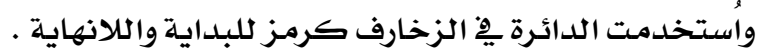
ب- الخط المقوس :-

القوس من الناحية الهندسية عبارة عن خط منحنى ، ويطلق الاسهم بصفة خاصسة على جـزء

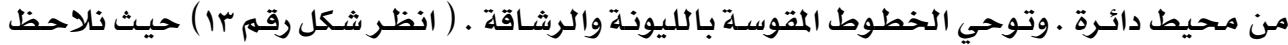

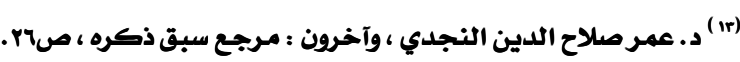

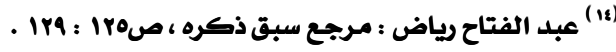

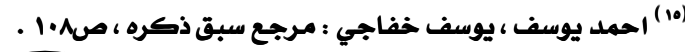




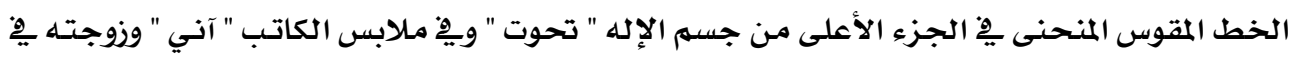

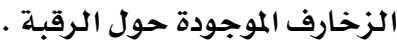

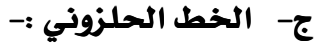

الزخرفة الحلزونية تأتى بعد اللوتس ِِِ الأهمية يِّ فن الزخرفة المصرية القديمة ، وقد أوجد

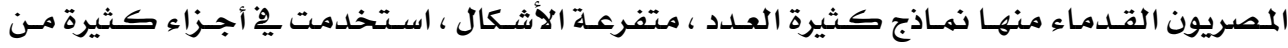

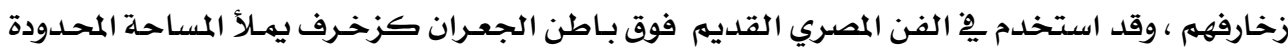

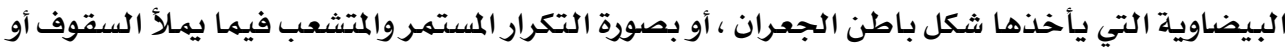

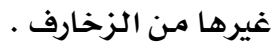

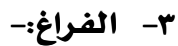

الفـراغ ِِِ العمـل الفـني هو عكس الكتلـة ، أو كمها يحلـو لبعض الفنـانين والنقـاد أن يسموه

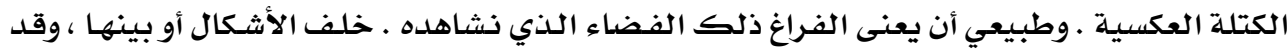

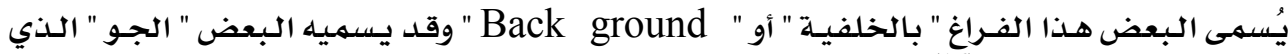

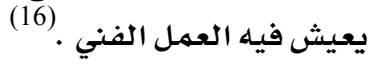

وٌِِ الفن المصري القديم نجد الاهتمام بالفراغ له نفس الاهتمام بالشكل ، ونشعر أن الفـراغ

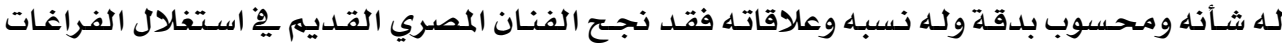

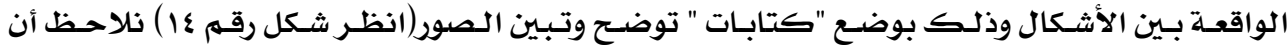

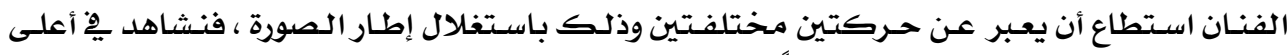

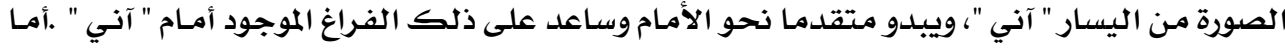

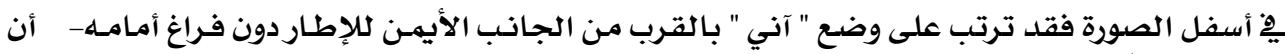

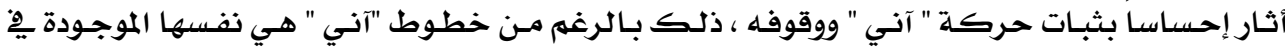

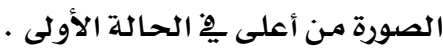

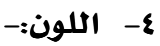

يعتبر اللـون مسن عناصـر التشكيل أو التكوين الأسـاسية ودراسـة اللـون مـن النـاحيـة النظريـة

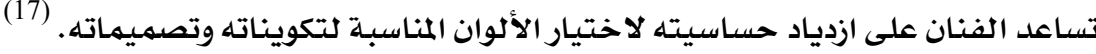

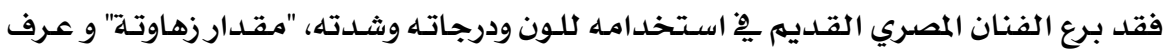

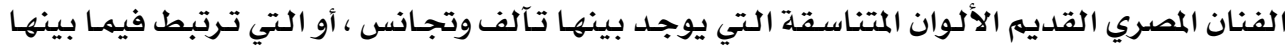

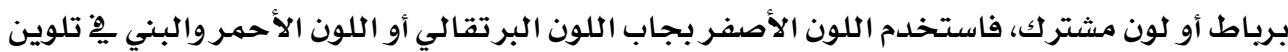

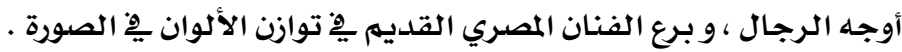

(17) د.عمر صلاح الدين النجدي وآخرون : مرجع سبق ذكره ، صعه .

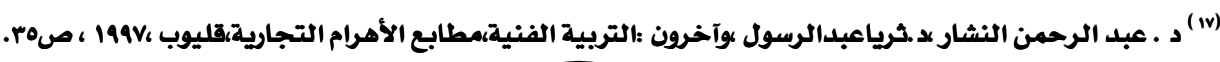




\section{نتائج البحث}

\section{يمكن تلخيص نتائج البحث ـية :}

ا ـ أثبتت الدراسة بأن الفنان المصري القديهم كان على دراية كبيرة بالأسس والعناصـر المستخدمـة

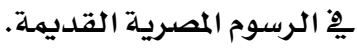

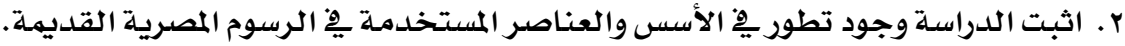

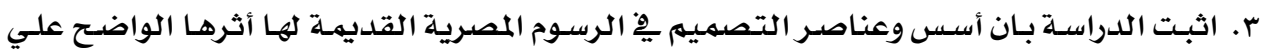

أسس عناصر التصميهم يُ العصر الحديث من حيث التكوين والحس الفني •

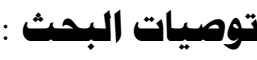

ا ـ ضرورة الاستفادة مـن خصائص الفـن المصري القديم ، والاهتهـام بالرسـوم الموجـودة ِِِ البرديات

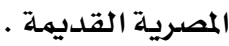

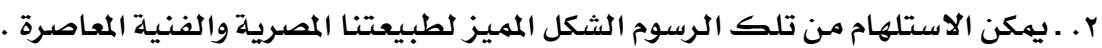

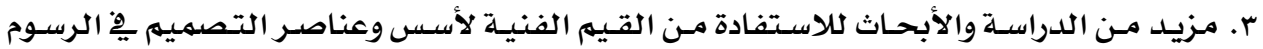

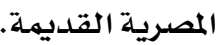

1 ا ـ أحمد يوسف ، يوسف خفاجي : فن الزخرفة المصرية القديمة ،مكتبة مد بولي ،القاهرةببدون تاريخ

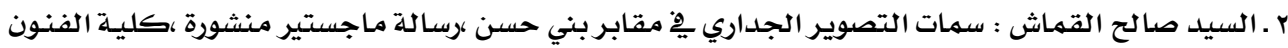

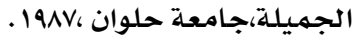

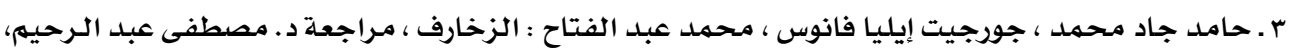

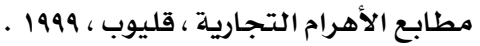

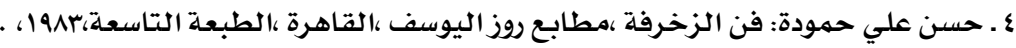

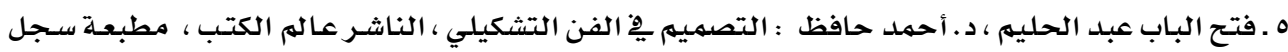

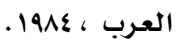

7 ـ عبد الفتاح رياض: التكوين ِِِ الفنون التشكيلية ، دار النهضة العربية ، الطبعة الثالثة ، القاهرة 1990، .

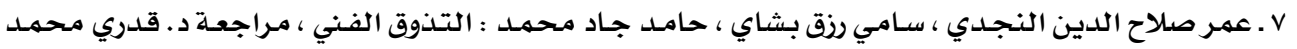

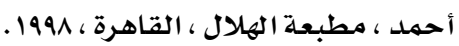

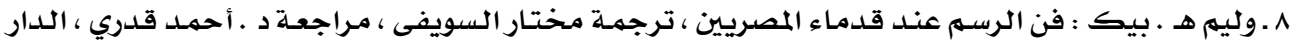

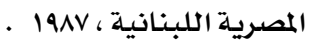




\section{هلحق الصور}

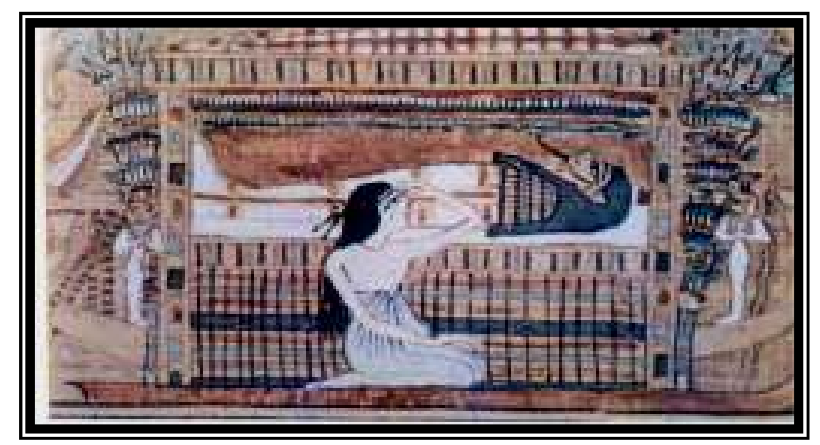

شكل رقم ا (مومياء آني يِ الموكب الجنائزي)
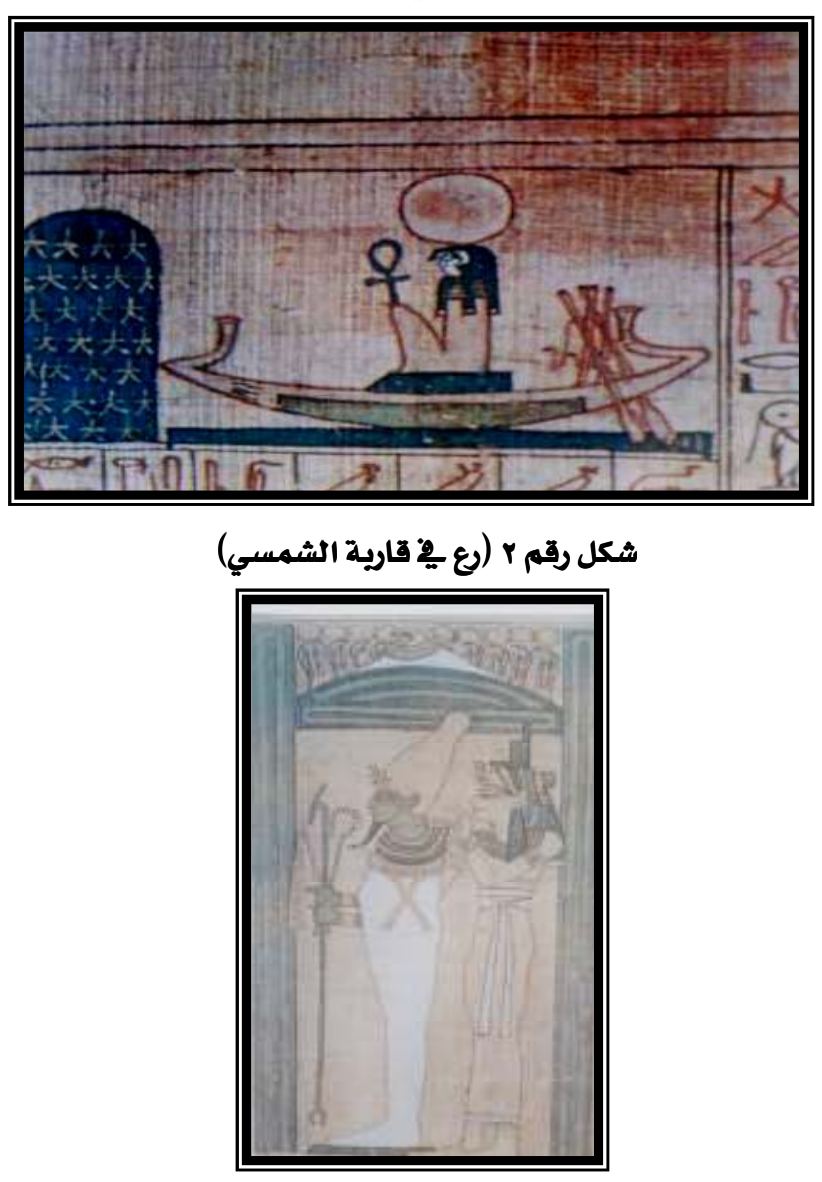


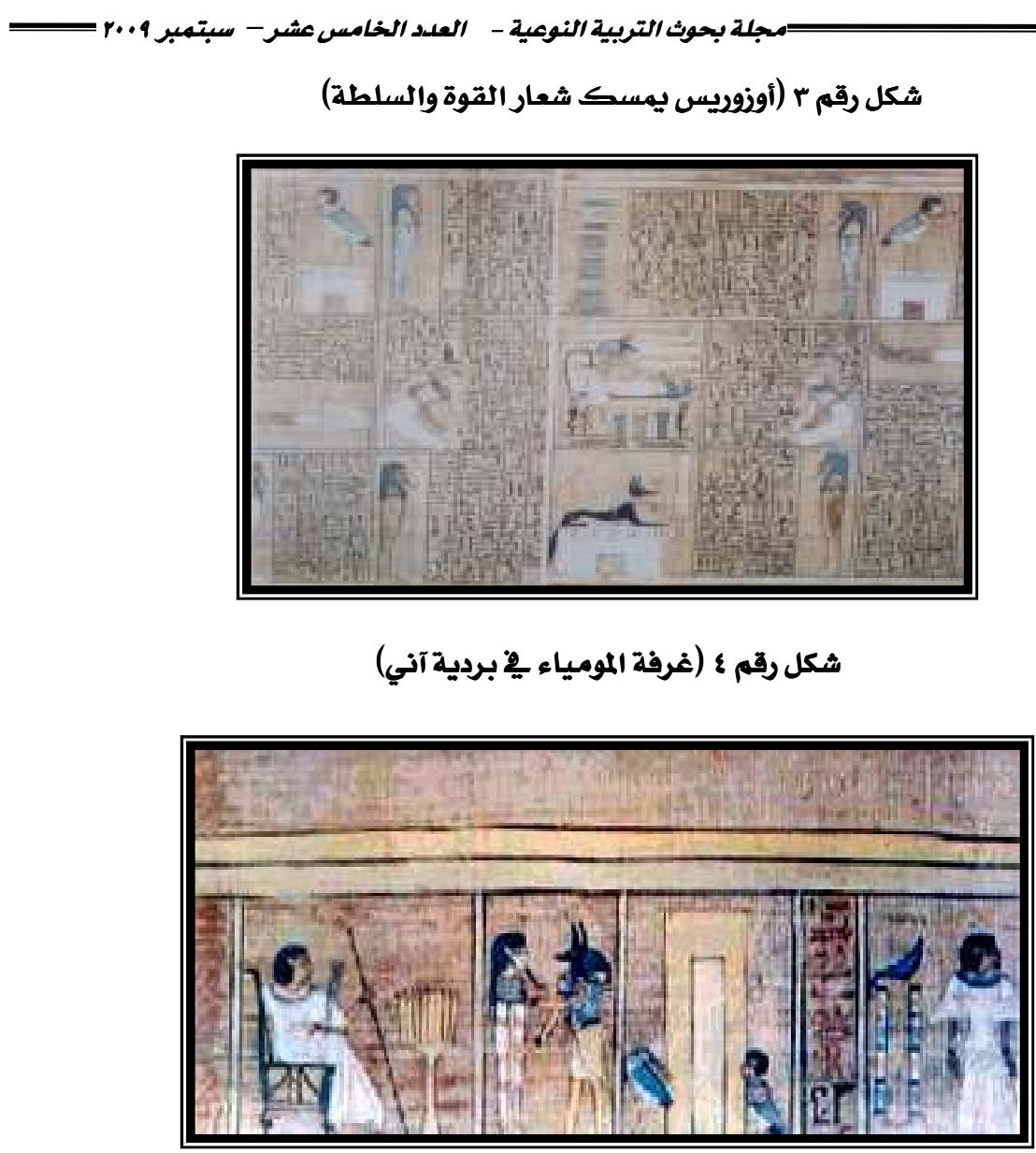

شكل رقم ه (عدم الدخول إلى صخرة الذبح)

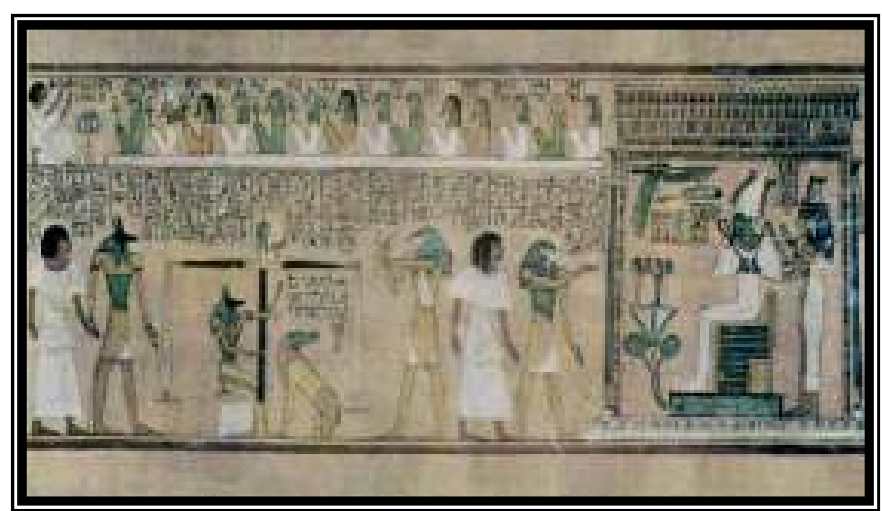

شكل رقم ح (منظر المحاكمة) 


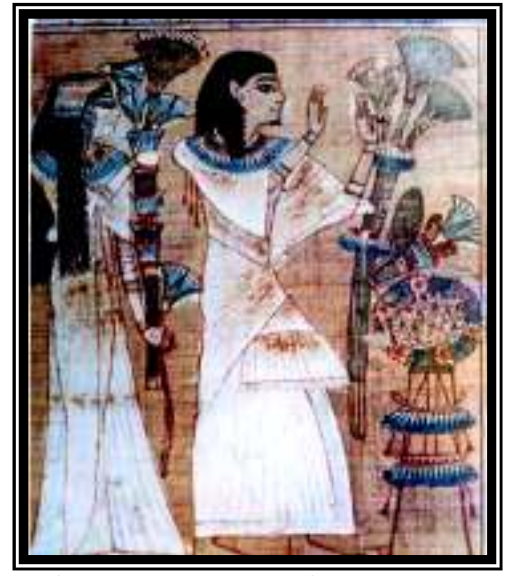

شكل رقم v (آني وزوجته يبتهلان)

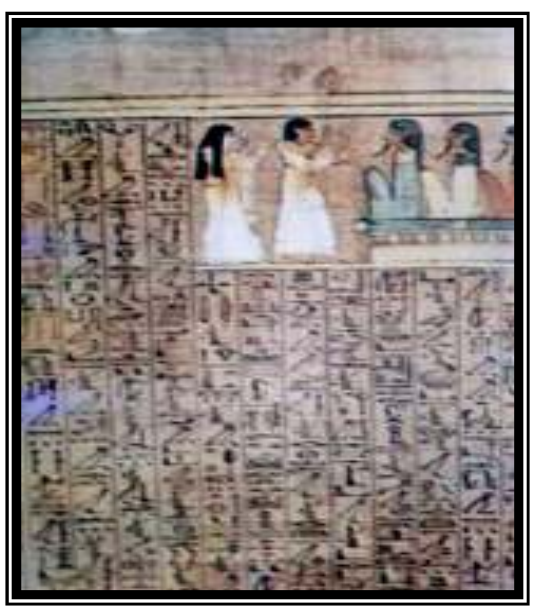

شكل رقم ^ (أبناء حورس)

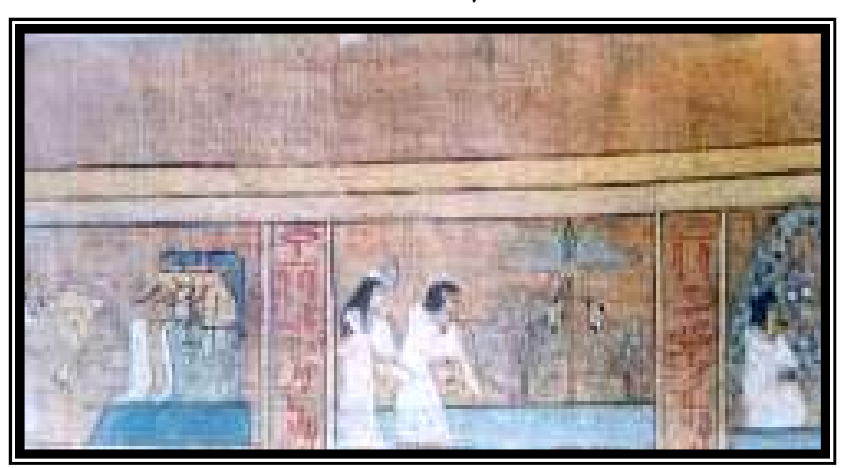

شكل رقم ه (عدم السماح لقلب المرء أن يؤخذ منه) 


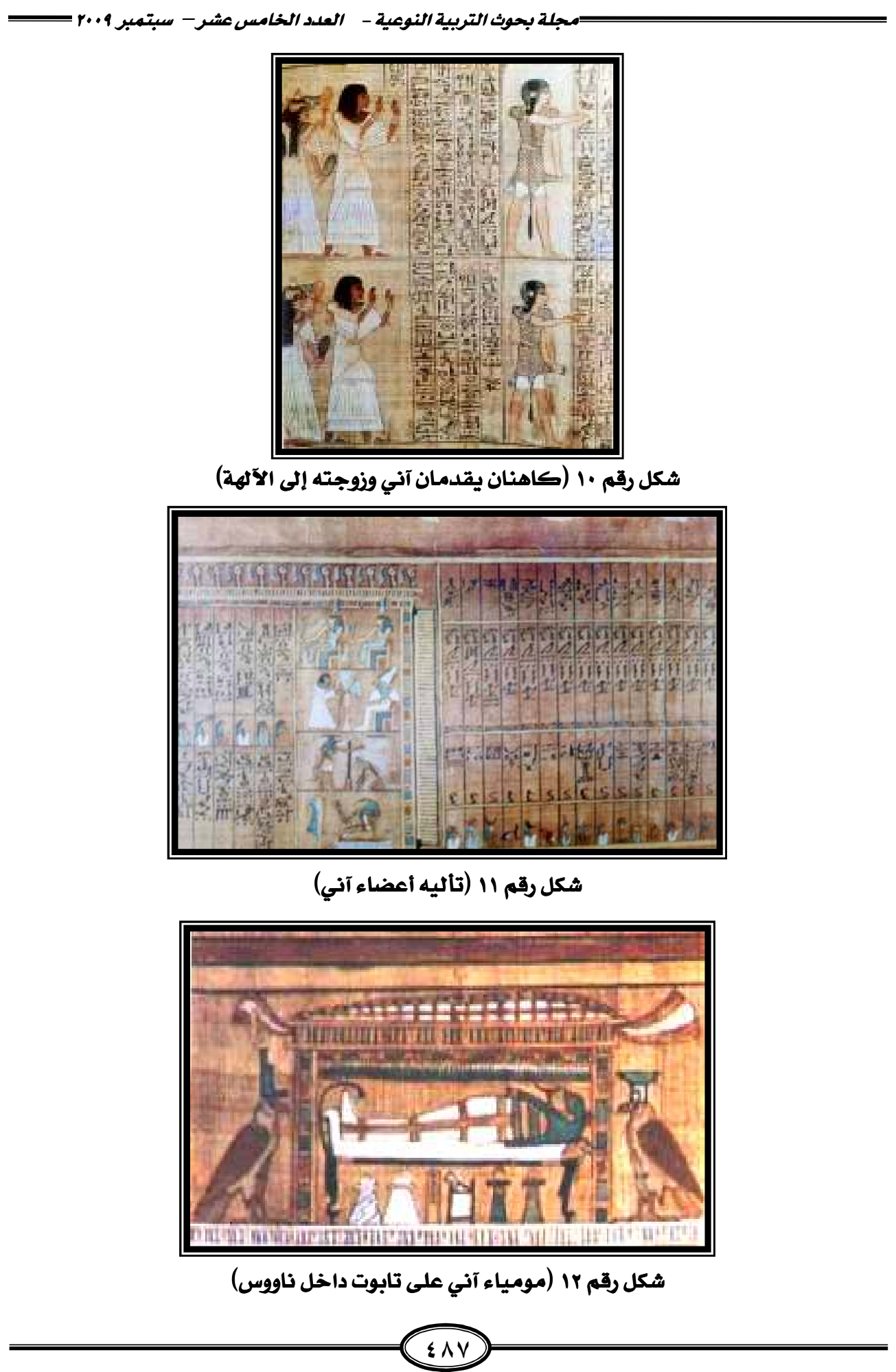




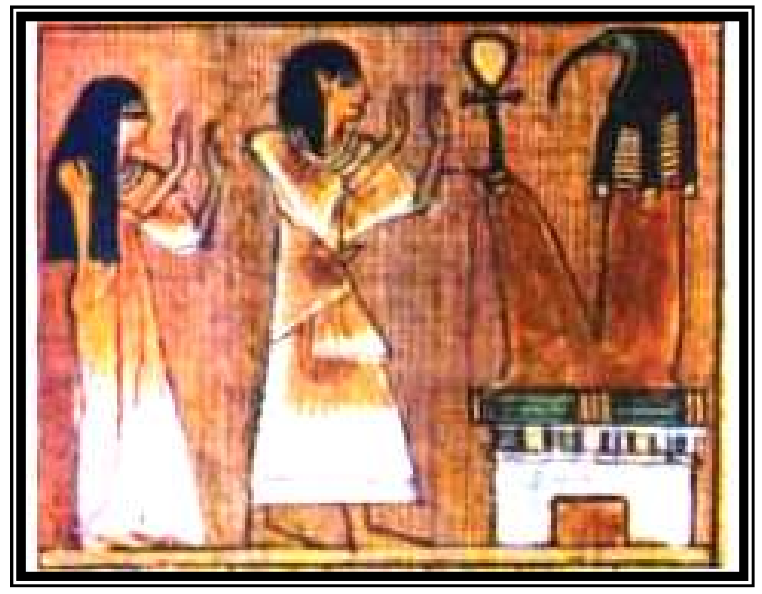

شكل رقم זا (آني وزوجته يبتهلان إلى تحوت)

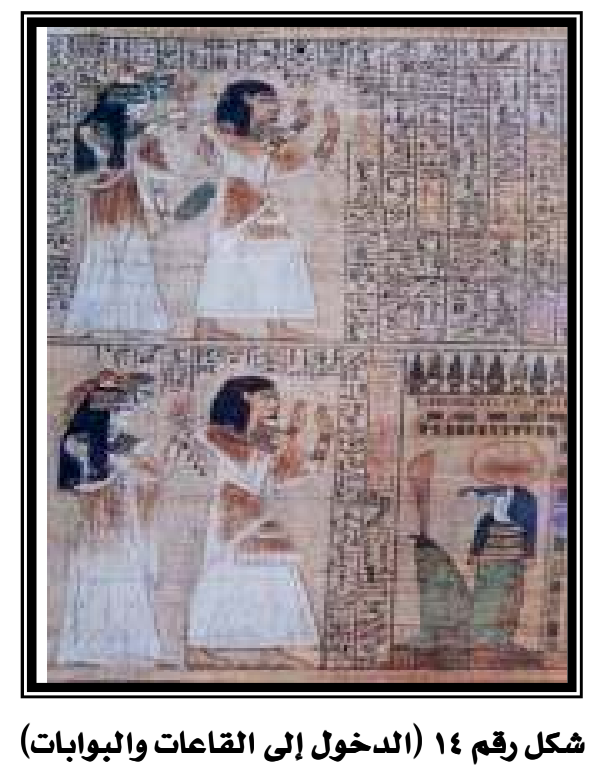

